Received: 10.07 .2018

Revised: 06.08.2018

Accepted: 31.08 .2018

DOI: $10.17804 / 2410-9908.2018 .5 .018-037$

\title{
REGULARITIES IN THE FORMATION OF STRUCTURAL STATES AND HYDRODYNAMIC FLOWS IN COPPER AND STEEL AT THE COLLAPSE OF CYLINDRICAL SHELLS UNDER THE EXPLOSION ACTION
}

\author{
V. I. Zeldovich ${ }^{1 *}$, N. Yu. Frolova ${ }^{1}$, A. E. Kheifets ${ }^{1}$, \\ I. V. Khomskaya ${ }^{1}$, S. M. Dolgikh ${ }^{2}$, E. B. Smirnov ${ }^{2}$, \\ A. A. Degtyarev ${ }^{2}$, and E. V. Shorokhov ${ }^{2}$ \\ ${ }^{I}$ M. N. Miheev Institute of Metal Physics, Ural Branch of the Russian Academy of Sciences, \\ 18 S. Kovalevskoy St., Ekaterinburg, Russian Federation \\ ${ }^{2}$ Russian Federal Nuclear Center-Academician E. I. Zababakhin All-Russian Research Institute of Technical Physics, \\ 13 Vasilieva St., Snezhinsk, Chelyabinsk Region, Russian Federation \\ *Corresponding author. E-mail: zeldovich@imp.uran.ru \\ Address for correspondence: 18, ul. S. Kovalevskoy, 620137, Ekaterinburg, Russian Federation \\ Tel.: +7 3433783554
}

The collapse of copper and steel shells (pipes) into solid cylinders under the action of explosion is investigated. The phase and structural transformations occurring in materials affected by high-speed deformation during collapsing are studied; fracture phenomena associated with the release of a shock wave onto the free inner surface of the shell are investigated. It is shown that the convergence of shells of large diameter proceeds more steadily; it is established that the stability of convergence depends on the absolute dimensions of the shell rather than on the relative ones. It is shown that comparing the results of experiments on collapsing shells from various materials makes it possible to recreate partially the loading conditions that were not recorded directly in the experiment, in particular, to calculate the mass velocity of the shell and the pressure in the front of the shock wave.

Keywords: collapse of shells, high-speed deformation, shock-wave loading, copper, steel, microstructure.

\section{Acknowledgment}

The submicroscopic study was performed with the equipment of the Nanotechnologies and Advanced Materials Testing Center collective use center of IPM UB RAS.

The work was supported by the UB RAS Complex Program (project 18-10-2-39).

\section{Reference}

1. Zababakhin E.I., Zababakhin I.E. Yavleniya neogranichennoy kumulatsii [Unlimited Cumulation Phenomenon]. M., 1988, 172 p. (In Russian).

2. Ivanov A.G., Ogorodnikov V.A., Tyunkin E.S. Behavior of shells affected by pulse loading. Small disturbances. Zhurnal Eksperimentalnoy $i$ Teoreticheskoy, 1992, no. 6, pp. 112-115. (In Russian).

3. Zeldovich V.I., Frolova N.Yu., Kheifets A.E., Dolgikh S.M., Gaan K.V., Shorokhov E.V. Deformation- and temperature-related processes that occur upon the collapse of a thick cylindrical shell made of steel 20. Physics of Metals and Metallography, 2015, vol. 116, pp. 285-292. DOI: 10.7868/S001532301503016X.

4. $\quad$ Ogorodnikov V.A. Vyazkost $i$ ee rol v dinamicheskikh protsessakh [Viscosity and its Role in Dynamic Processes]. Sarov, FGUP RFYaTs-VNIITF, 2012, 239 p. (In Russian). 
5. Udarnye volny $i$ yavleniya vysokoskorostnoy deformatsii metallov [Shock Waves and HighRate Deformation Phenomena in Metals], ed. by Marc A. Meyers and Lawrence E. Murr. M., Metallurgy, 1984, 512 p. (In Russian).

6. Rybin V.V., Ushanova E.A. Features of twinning under high-speed loading conditions during explosion welding. Letters on Materials, 2013, vol. 3 (2), pp. 145-149. DOI: 10.22226/24103535-2013-2-145-149.

7. Rybin V.V., Ushanova E.A., Zolotorevsky N.Yu. Features of the arrangement of misoriented structures in a $\mathrm{Cu}-\mathrm{Cu}$ bilayer plate produced by explosion welding. J. Tekhn. Phyz., 2013, vol. 83, iss. 9, pp. 63-72. (In Russian).

8. Zeldovich Ya.B., Raizer Yu.P. Physika udarnykh voln $i$ vysokotemperaturnykh gidrodinamicheskikh techeniy [Physics of Shock Waves and of High-Temperature Hydrodynamic Flows]. M., Phizmatgiz, 1963, 632 p. (In Russian).

9. Glazkov V.S., Ignatova O.N., Malyshev A.N., et al. Method for research onmicroand mrsoscale high-rate deformation of metals. Phys. Mesomechanics, 2011, vol.14, iss. 3-4, pp. 178-184.

10. Shock Wave Data Base. Available at: http://www.ihed.ras.ru/rusbank/ 
Подана в журнал: 10.07 .2018

УДК 669.3:621.7.044:620.186

DOI: $10.17804 / 2410-9908.2018 .5 .018-037$

\title{
ЗАКОНОМЕРНОСТИ ФОРМИРОВАНИЯ СТРУКТУРНЫХ СОСТОЯНИЙ И ГИДРОДИНАМИЧЕСКИХ ТЕЧЕНИЙ В МЕДИ И СТАЛИ ПРИ СХОЖДЕНИИ ЦИЛИНДРИЧЕСКИХ ОБОЛОЧЕК ПОД ДЕЙСТВИЕМ ВЗРЫВА
}

\author{
В. И. Зельдович ${ }^{1, a^{*}}$, Н. Ю. Фролова ${ }^{1, \text { б) }}$ А. Э. Хейфец ${ }^{1, \text { в) }}$ \\ И. В. Хомская ${ }^{1, \text { г) }}$, С. М. Долгих ${ }^{2, \text { д) }}$, Е. Б. Смирнов ${ }^{2, \text { e) }}$, \\ А. А. Дегтярев ${ }^{2, ж)}$ Е. В. Шорохов ${ }^{2,3)}$ \\ ${ }^{1}$ Институт физики металлов УрО РАН, 620137, Екатеринбург, ул. С. Ковалевской, 18 \\ ${ }^{2}$ РФЯЦ-ВНИИ технической физики им. акад. Е.И. Забабахина, \\ 456770, Снежинск, Челябинской обл., а/я 245 \\ *Ответственный автор. Электронная почта: zeldovich@imp.uran.ru \\ Адрес для переписки: ул. С. Ковалевской, 18,620990, Екатеринбург, Российская Федерация \\ Тел.: +7 (343) 378-35-54
}

Исследовано схлопывание медных и стальной оболочек (труб) в сплошные цилиндры под действием взрыва. Изучены фазовые и структурные превращения, протекающие в материалах под действием высокоскоростной деформации при схлопывании; исследованы откольные явления, связанные с выходом ударной волны на свободную внутреннюю поверхность оболочки. Показано, что схождение оболочек большого диаметра протекает более устойчиво; установлено, что устойчивость схождения зависит не от относительных, а от абсолютных размеров оболочки. Показано, что сопоставление результатов экспериментов по схлопыванию оболочек из различных материалов позволяет частично воссоздать условия нагружения, незарегистрированные непосредственно в ходе эксперимента, в частности, вычислить массовую скорость оболочки и давление во фронте ударной волны.

Ключевые слова: схлопывание оболочек, высокоскоростная деформация, ударно-волновое нагружение, медь, сталь, микроструктура.

\section{1. Введение}

Исследование схлопывания металлических цилиндрических оболочек под действием взрыва представляет собой одно из направлений изучения явления кумуляции $[1,2]$. Схлопывание осуществляется под действием взрыва заряда взрывчатого вещества (BB), окружающего оболочку. При недостаточной мощности заряда ВВ полное схлопывание не происходит. В результате получается оболочка меньшего радиуса и большей толщины. При избыточной мощности заряда происходит кумуляция энергии, на завершающей стадии схождения скорость вещества неограниченно возрастает; в этом случае после схлопывания может произойти разлет оболочки. Особый интерес представляет случай, когда мощность ВВ подбирается таким образом, что происходит полное схлопывание оболочки, но к моменту окончания процесса схождения вся энергия ВВ оказывается израсходованной. В этом случае в результате схлопывания удается получить сплошной цилиндр без следов разрушения, связанных с кумуляцией. При этом специфические условия нагружения (ударно-волновое воздействие и высокоскоростная деформация, величина и скорость которой изменяются вдоль радиуса цилиндра в широких пределах) приводят к формированию необычных структурных состояний в нагружаемом материале. Исследования этих структурных состояний представляют несомненный интерес для физического материаловедения и понимания физики процессов, происходящих в материале при высокоскоростном деформировании. Таким образом, схлопывание оболочек является одним из методов, позволяющих изучать структуру и свойства метал- 
лов и сплавов при деформировании со скоростями порядка $10^{5} \mathrm{c}^{-1}$; при этом значительное изменение степени деформации вдоль радиуса позволяет исследовать деформационное поведение материала в широком диапазоне степеней высокоскоростной деформации на одном образце.

Важно подчеркнуть, что при схлопывании оболочки под действием взрыва, несмотря на высокую скорость протекающих процессов, в отличие от большинства других видов ударно-волнового нагружения, деформация материала осуществляется квазиадиабатически. Процесс нагружения оболочки можно разделить на два этапа, отличающихся по времени. Первый этап состоит в действии ударной волны на материал оболочки. При скорости ударной волны $\sim 5$ км/с и толщине стенки оболочки $\sim 5$ мм он длится 1-2 мкс. Второй этап начинается одновременно с первым и состоит в инерционном схождении оболочки. На этом этапе происходит высокоскоростная деформация и оболочка преобразуется в цилиндр. Длительность второго этапа на порядок больше первого. На втором этапе материал движется по инерции, без подвода энергии извне. При этом скорость деформации хотя и велика, но существенно меньше, чем в ударных волна и сверхзвуковых гидродинамических течениях. В движущемся по инерции веществе успевают происходить релаксационные процессы, возникают закономерные (обусловленные геометрией эксперимента) эффекты локализации деформации и формируются сложные гидродинамические течения, приводящие к изменению формы оболочки $[3,4]$. Таким образом, эксперименты по схлопыванию оболочек занимают промежуточное положение между экспериментами по ударно-волновому нагружению и квазистатическим деформированиям.

Процесс схождения оболочки, как правило, не является идеально осесимметричным. При изменении радиуса и толщины на поверхности сходящейся оболочки возникают возмущения, обусловленные неустойчивостью течения материала. Поверхность оболочки становится волнистой. Количество, форма и амплитуда волн зависят от свойств материала и геометрии эксперимента. Соответствующие возмущения наблюдаются и в объеме, проявляясь в структуре нагруженных образцов в виде эффектов локализованной деформации. В научной литературе известны попытки теоретического описания развития неустойчивости при схождении на основе различных упруго-пластических и ударноволновых моделей, однако, как отмечается в [4], «В целом надо признать справедливость утверждения о том, что в настоящее время отсутствуют общепризнанные критерии... неустойчивого движения оболочек».

Цель работы - макро- и микроструктурное исследование деформационного поведения и механизмов изменения формы оболочек при схождении в зависимости от геометрии нагружения и свойств нагружаемого материала. Поскольку параметры ударно-волнового воздействия (давление, начальная массовая скорость, остаточная температура) не всегда поддаются точной регистрации в процессе эксперимента, дополнительно оценивались указанные параметры по остаточным изменениям в структуре нагруженных образцов. При таком подходе нагружаемый образец является не только объектом исследования, но и своеобразным инструментом, фиксирующим в микроструктуре недоступные прямому наблюдению высокоскоростные процессы, протекающие в микросекундные интервалы времени.

\section{2. Материал и методика исследования}

Исходная длинная оболочка из меди марки М1 диаметром 130 мм и толщиной стенки 5,9 мм была окружена цилиндрическим слоем бризантного взрывчатого вещества. Слой ВВ был окружен другой концентрически расположенной цилиндрической оболочкой (корпусом) из стали 20 (Fe-0,2 вес. \% C) Корпус задерживал разлет продуктов взрыва и увеличивал время действия высокого давления. Инициирование взрыва осуществляли с торца ВВ с помощью кольцевой системы инициирования через промежуточное высокочувствительное бри- 
зантное ВВ. После инициирования ВВ вдоль медной оболочки распространялась скользящая детонационная волна, под действием которой происходило схождение оболочки к оси симметрии. По аналогичной схеме была нагружена оболочка из стали 20 [3]. Диаметр стальной оболочки был 118 мм, толщина стенки 5,7 мм. Некоторые различия в размерах оболочек и параметрах нагружения были обусловлены тем, что условия эксперимента эмпирически подбирали таким образом, чтобы добиться полного схождения оболочек из материалов с различными прочностными свойствами, без избытка подводимой энергии. При нагружении стальной оболочки проводилась высокоскоростная рентгеновская съемка процесса схождения, кроме того, скорость оболочки регистрировали с помощью системы электроконтактных датчиков. Таким образом, параметры нагружения стальной оболочки были известны. Регистрация процесса схождения медной оболочки не проводилась; недостающие параметры нагружения предполагалось получить из сравнения результатов двух экспериментов.

Для выявления влияния связи размера оболочки и развивающейся при схождении неустойчивости течения была нагружена медная оболочка диаметром 48 мм и толщиной стенки 4 мм. Как и в двух других опытах, путем эмпирического подбора параметров нагружения добивались полного схождения оболочки без эффектов кумуляции. В процессе эксперимента проводилась рентгеновская регистрация процесса схлопывания.

Медные оболочки были приготовлены из отожженных прутков, исходная недеформированная микроструктура состояла из зерен размером 200-300 мкм с многочисленными двойниками отжига.

Для исследования макро- и микроструктуры и измерения микротвердости были выполнены поперечные разрезы полученных при схлопывании цилиндров. Металлографические исследования выполняли на микроскопе EPITYP 2, измерение микротвердости на приборе ПМТ-3 при нагрузке 0,49 Н для меди и 0,98 Н для стали.

\section{3. Результаты исследования и их обсуждение}

Медная оболочка большого диаметра. В результате нагружения медной оболочки диаметром 130 мм был получен цилиндр диаметром 57-58 мм.

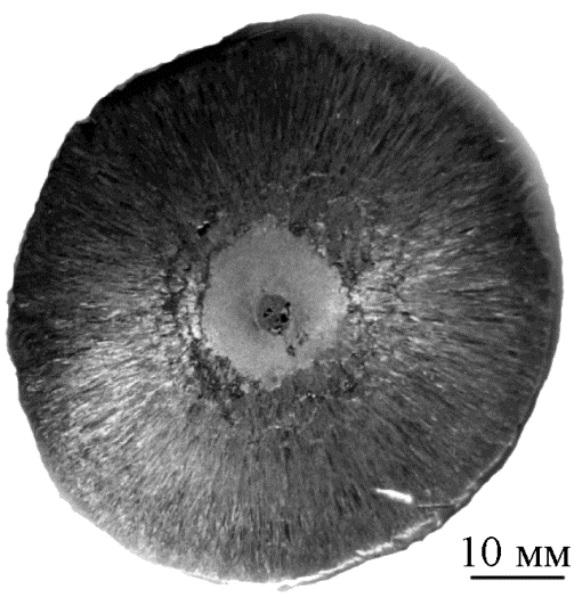

Рис. 1. Макроструктура схлопнутого цилиндра в поперечном сечении

В макроструктуре поперечного сечения (рис. 1) видны три кольцевые зоны, свидетельствующие об осесимметричном характере радиальной деформации. Наружная кольцевая зона занимает бо́льшую часть сечения, распространяясь от поверхности цилиндра до радиуса 8 мм. Картина течения в этой зоне показывает, что деформация схождения происходила строго в радиальном направлении, что обеспечивало симметричное схлопывание оболочки, заметных возмущений, и неустойчивости течения не наблюдалось. Во внутренней части этой зоны, от радиуса 12 мм до радиуса 8 мм, видна область трещин, расположенных преимуще- 
ственно в тангенциальном направлении. Следующая зона, которая выглядит светлой, распространяется от радиуса 8 мм до радиуса 2 мм, это зона рекристаллизации. Внутренняя, центральная зона имеет форму круга с радиусом 2 мм и гладкую границу с предыдущей зоной. Она содержит небольшие поры размером менее 1 мм. В этой зоне происходило плавление и последующая кристаллизация.

Исследование микроструктуры позволило установить некоторые особенности высокоскоростной деформации схождения в меди, не наблюдавшиеся в стальном цилиндре [3]. На рис. 2 представлены характерные снимки деформированной структуры в первой (наружной) зоне. Двойники разной направленности заполняют исходные зерна (кристаллиты) (рис. 2 a). Наличие большого количества двойников в структуре указывает на то, что в высокоскоростной деформации и образца имело место двойникование. Это объясняется не только высокой скоростью деформации, но и тем обстоятельством, что деформация схождения происходит в условиях сжимающих напряжений. В то же время, изгибы двойников, указанные стрелками на рис. 2 6, 2 в, свидетельствуют о том, что деформация осуществляется не только двойникованием, но и скольжением. Зерна удлиняются в радиальном направлении, анизотропия зерен достигает 10:1 и более. Хотя на макроуровне радиальная деформация является однородной, на мезоуровне она происходит неоднородно, наряду с сильно деформированными участками и зернами встречаются слабо деформированные. Неоднородность деформации проявляется также на микроуровне, в пределах одного зерна. Так, на рис. 26 и в показаны двойники искривленной формы. Ранее возникшие прямолинейные двойники приобретают такую форму вследствие разной скорости течения в одном зерне. Разная длина стрелок на рис. 2 в показывает разную скорость течения по радиусу. По виду двойниковой структуры можно определить последовательность образования двойников.

Так, на рис. 2 г представлены двойники трех направлений. Очевидно, что более широкие протяженные двойники (1) возникли первыми, затем возникли двойники второго направления, и затем тонкие короткие двойники, расположенные между первыми и вторыми (3). Заметим, что двойникование происходит вначале под действием ударной волны и затем при высокоскоростной деформации схождения.

Важно отметить, что в обычных (квазистатических) условиях при комнатной температуре деформация двойикованием не характерна для ГЦК металлов с высокой энергией дефектов упаковки, в частности, для меди. Тем не менее, в динамических условиях такие материалы могут деформироваться двойникованим под действием ударных нагрузок при давлениях выше некоторого критического значения. Для меди это критическое давление составляет 15-20 ГПа [5]. Кроме того, в работах $[6,7]$ при изучении деформационных эффектов в узкой приконтактной зоне соединения, полученного методом сварки взрывом двух медных пластин, было показано, что в условиях высокоскоростной деформации двойникование в меди может происходить даже в том случае, если критическое давление не достигается. Авторы $[6,7]$ отмечают, что «деформационное микродвойникование происходит тогда и там, когда и где на фоне уже сформировавшейся ячеистой структуры исчерпываются возможности релаксации взрывообразно нарастающих упругих напряжений за счет развития обычных дислокационных механизмов, и природа оказывается вынужденной запускать альтернативный и более динамичный процесс пластической деформации». По-видимому, при схлопывании оболочки под действием взрыва возможности релаксации упругих напряжений за счет дислокационных механизмов также оказываются исчерпанными. 


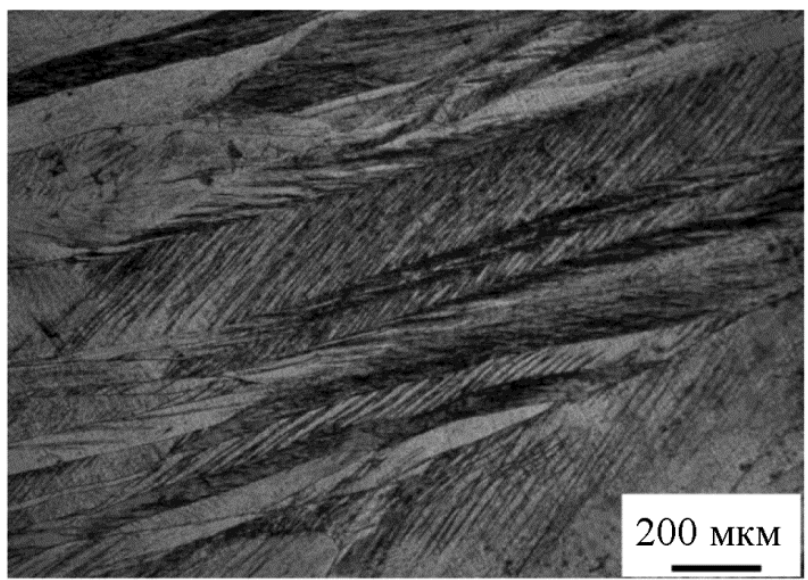

$a$

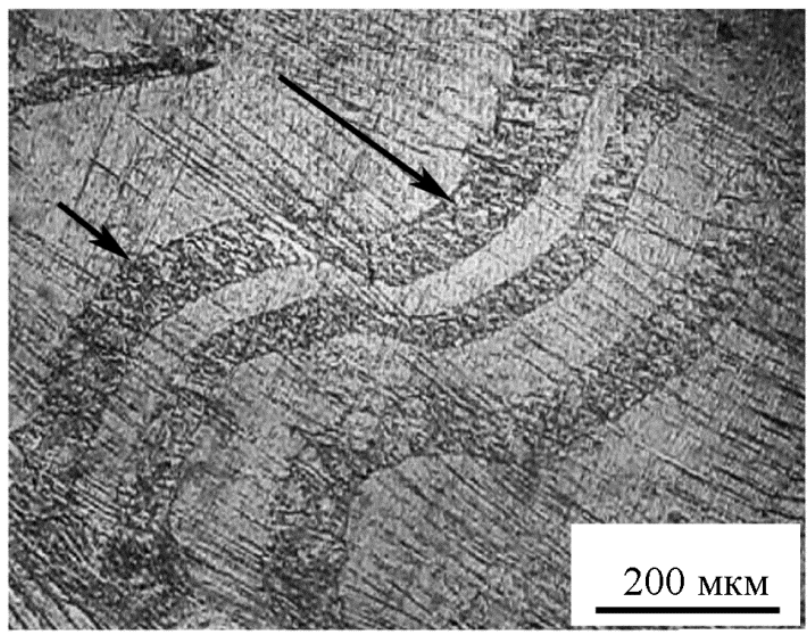

B

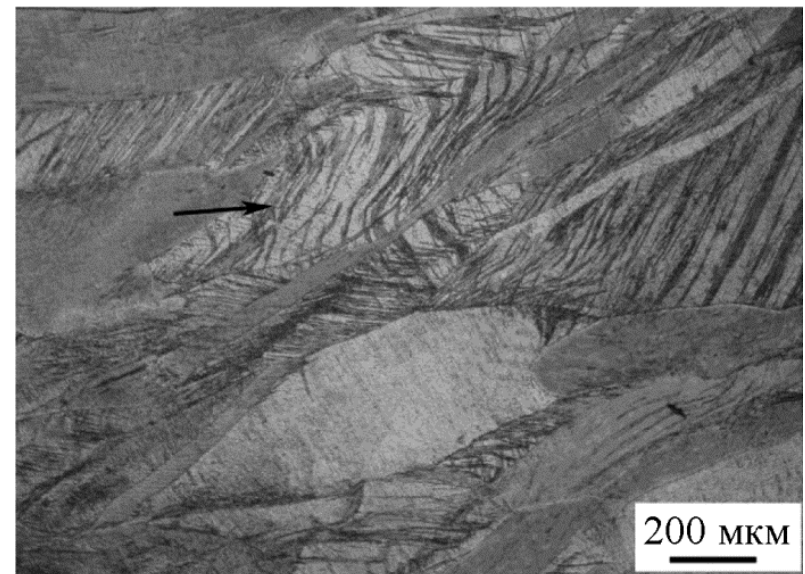

$\sigma$

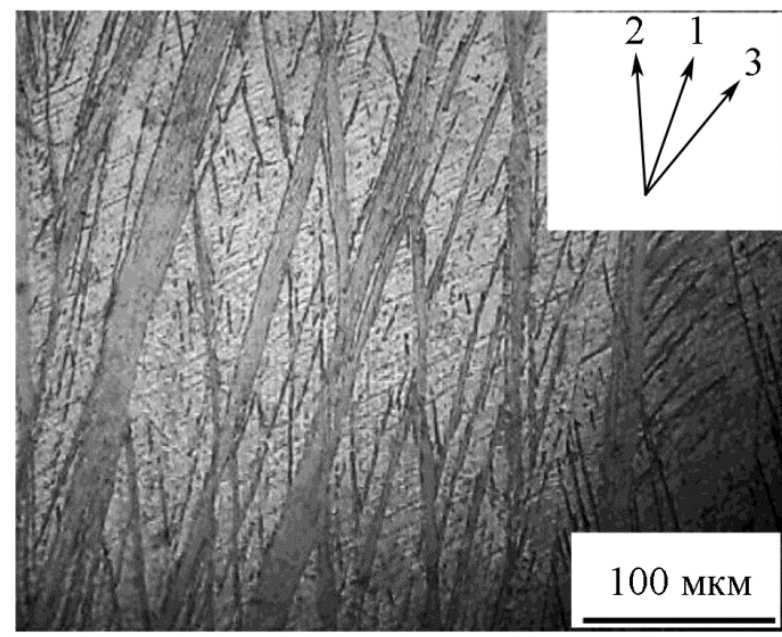

2

Рис. 2. Двойникование в зоне деформации. Участки с разной степенью деформации $(a, \sigma)$, изогнутые двойники (в), двойники трех направлений (2)

В зоне деформации наблюдается еще одна особенность структуры, связанная с наличием тангенциальных трещин. Как уже было отмечено, процесс нагружения оболочки скользящей ударной волной может быть разделен на два этапа. Первый этап состоит в действии ударной волны и длится несколько микросекунд. Второй этап начинается одновременно с первым, состоит в инерционном схождении оболочки и длится несколько десятков микросекунд, т. е. на порядок больше [3]. На первом этапе при выходе ударной волны с остроконечным профилем на свободную внутреннюю поверхность оболочки возникают значительные растягивающие напряжения, которые вызывают откольные явления [8]. На втором этапе при высокоскоростной деформации сжатия откольные трещины и микропоры залечиваются, но их следы сохраняются в структуре в виде участков хаотической деформации. Как будет показано ниже, многочисленные следы откольных явлений наблюдаются и в медной оболочке меньшего диаметра. На рис. 3 представлен след залеченной микротрещины в виде извилистой «пушистой линиии» не полностью залеченные микропоры (указаны стрелками). Залечивание происходит с образованием тонких коротких двойников, что соответствует данным работы [9]. 


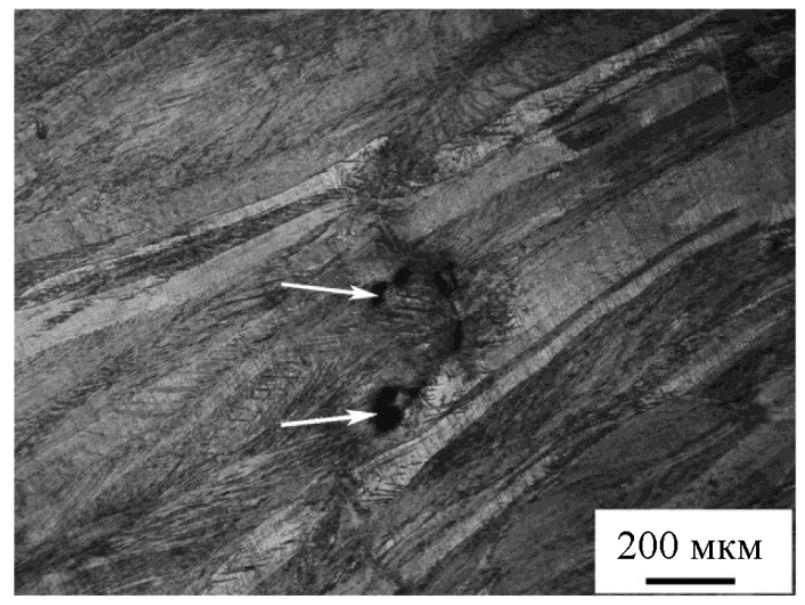

Рис. 3. Залеченная откольная микротрещина

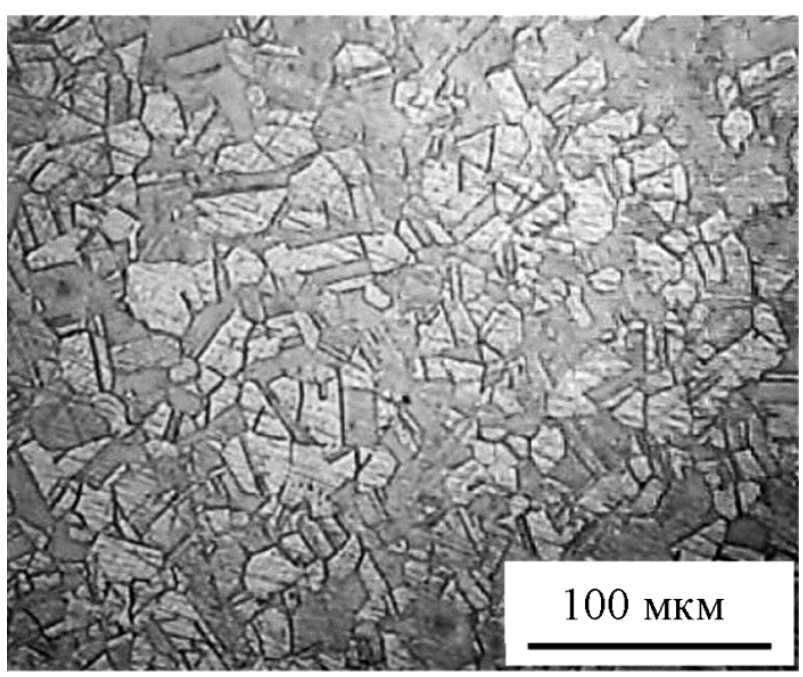

Рис. 4. Микроструктура в зоне рекристаллизации

Микроструктура во второй зоне (рис. 4) резко отличается от структуры в зоне деформации. Здесь отсутствуют признаки радиального течения, характерные для деформации схождения, хотя, несомненно, такая деформация имела место. Так как данный вид деформации сопровождается повышением температуры от поверхности к центру, то при определенной температуре нагрева включается процесс рекристаллизации и деформированная структура заменяется рекристаллизованной. Размер зерен составляет десятки микрометров, видны двойники отжига.

Структура третьей - центральной зоны - представлена на рис. 5. Структура состоит из однотипных столбчатых кристаллов. Иногда по границам кристаллов образуются протяженные трещины (рис. 5). Такая структура возникает при кристаллизации расплава, трещины имеют усадочное происхождение. Следовательно, в этой зоне медь испытала плавление и последующую кристаллизацию.

На рис. 6 (график) представлено изменение микротвердости вдоль радиуса цилиндра. В зоне деформации значение микротвердости характерно для сильно деформированной меди и составляет 1250 МПа. На границе зон деформации и рекристаллизации микротвердость резко уменьшается и становится равной 750 МПа. 


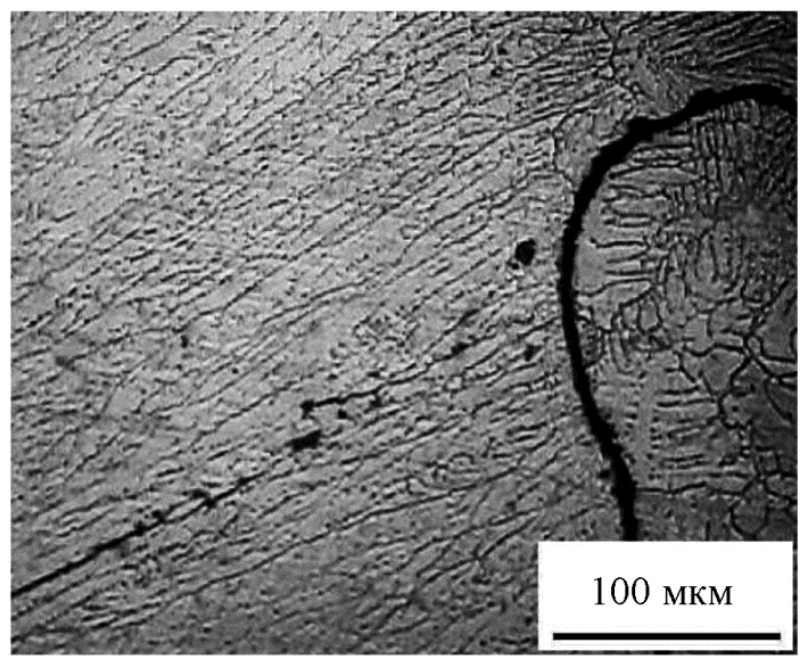

Рис. 5. Микроструктура в зоне кристаллизации
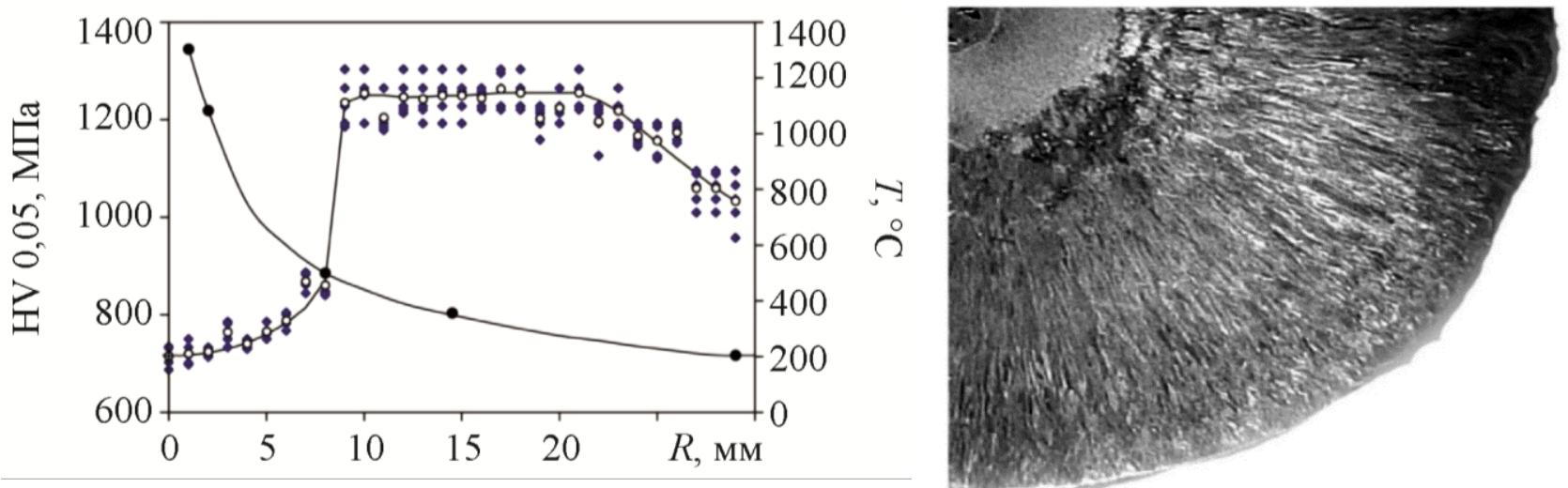

Рис. 6. Изменение макроструктуры, микротвердости и температуры вдоль радиуса в поперечном сечении схлопнутого цилиндра

Для определения степени основной, радиальной, деформации вначале найдем взаимное соответствие материальных точек, расположенных на оболочке и на схлопнутом цилиндре. Положение точки на оболочке обозначим радиусом $r$, на цилиндре - радиусом $R$. Взаимосвязь координат точек при условии центросимметричной деформации описывается соотношением

$$
R^{2}=r^{2}-r_{\mathrm{o}}^{2}
$$

где $r_{\mathrm{o}}$ - внутренний радиус оболочки [3]. Степень радиальной деформации можно определить, используя взаимосвязь расположения точек на оболочке и цилиндре. Истинная радиальная деформация $e$ вычисляется по соотношению

$$
e=\ln (r / R) \text {. }
$$

На поверхности цилиндра $e=0,8$; на половине радиуса $-1,4$; на расстояниях 8,2 и 1 мм от центра - 2,0; 3,4 и 4,1 соответственно. Естественно, что степень радиальной деформации сильно возрастает к центру (к оси) цилиндра.

При схлопывании оболочки высокоскоростная деформация происходит как адиабатический процесс, и практически вся энергия деформации переходит в теплоту и расходуется на нагрев материала оболочки. Как следует из наблюдения макроструктуры (рис. 1), температура на границе второй и третьей зон (на расстоянии 2 мм от центра) равна температуре 
плавления меди $\left(108{ }^{\circ} \mathrm{C}\right)$. Температура на границе первой и второй зон равна температуре рекристаллизации меди в данном эксперименте. Так как температура рекристаллизации зависит от многих факторов (от времени выдержки при температуре нагрева, от степени и вида деформации и др.), были выполнены специальные опыты по определению этой температуры. Из зоны деформации (с максимальным значением микротвердости) были приготовлены небольшие образцы размером в несколько миллиметров и подвергнуты кратковременному отжигу (в течение $\sim 1$ мин) при температурах в интервале $150-500{ }^{\circ} \mathrm{C}$. Измерения микротвердости образцов показали, что в условиях этого эксперимента температура рекристаллизации равна $500{ }^{\circ} \mathrm{C}$.

Используя полученные значения температур для двух реперных точек (температура плавления и температура рекристаллизации) на радиусе цилиндра и предполагая, что температура пропорциональна степени деформации, можно рассчитать изменение температуры вдоль радиуса. Радиальная зависимость степени деформации вычисляется непосредственно из геометрии схождения, а коэффициент пропорциональности между степенью деформации и температурой вычисляется по имеющимся реперным точкам (температуры на внешних границах зон плавления и рекристаллизации, радиусы зон известны). На рис. 6 представлена суммарная картина изменения вдоль радиуса макроструктуры, микротвердости и температуры. Отчетливо видна корреляция приведенных характеристик. Температура на расстоянии 1 мм от центра, полученная при экстраполяции, достигает $1300{ }^{\circ} \mathrm{C}$.

Стальная оболочка. При нагружении стальной оболочки был получен сплошной цилиндр диаметром $\sim 50$ мм. Скоростная рентгеновская съемка (рис. 7) и электроконтактная регистрация процесса схождения позволили установить следующие параметры эксперимента. Время схлопывания в одном сечении было 30-35 мкс. В начальный момент времени оболочка перемещалась со скоростью $\sim, 8$ км/с. Это значение массовой скорости соответствует давлению в ударной волне 20 ГПа [3].

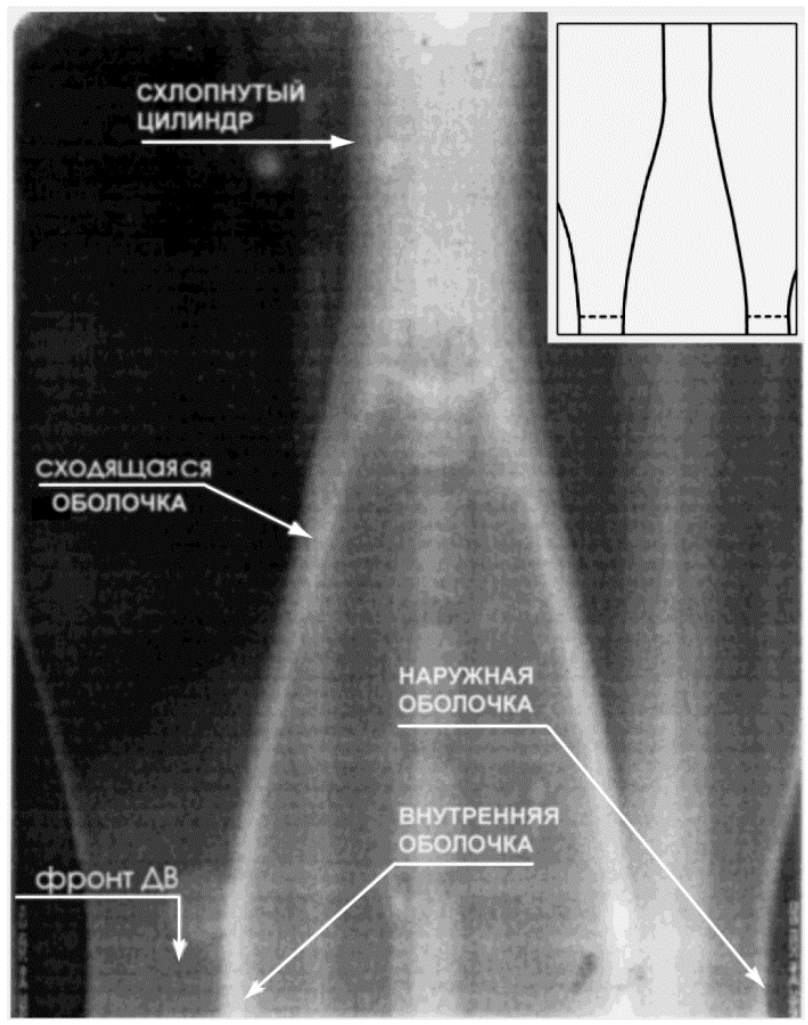

Рис. 7. Рентгеновский снимок процесса схождения оболочки и его схема 


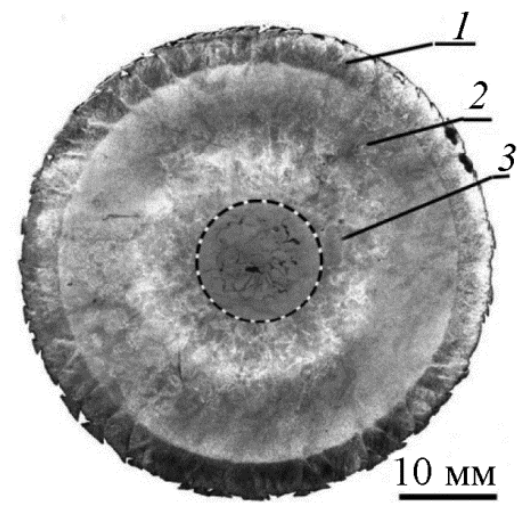

$a$

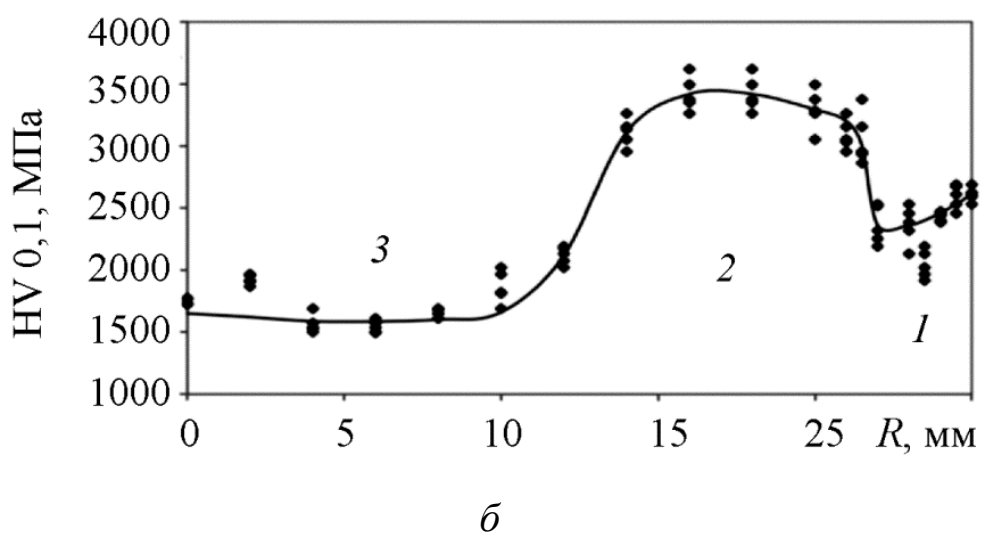

Рис. 8. Макроструктура цилиндра в поперечном сечении $(a)$ и изменение микротвердости по его радиусу (б): 1, 2, 3 - соответствующие зоны. Штриховой линией в центральной части цилиндра обведена зона неустойчивого течения

На рис. 8 представлена макроструктура схлопнутого цилиндра в поперечном сечении и изменение микротвердости вдоль радиуса. Вид макроструктуры и ход микротвердости, также как и в медной оболочке, указывают на существование трех кольцевых зон, свидетельствующих об осесимметричном характере нагружения. Граница первой, наружной зоны и второй - резкая, и характеризуется скачкообразным изменением микротвердости. Граница второй и третьей (центральной) зоны - нерезкая, и микротвердость изменяется плавно. В центральной части третьей зоны (вблизи оси цилиндра) устойчивость движения нарушается, течение вещества перестает быть осесимметричным. Об этом свидетельствует сильная локализация деформации в этой области, носящая явно не осесимметричный характер. На рис. 8 а область потери устойчивости отмечена пунктирной линией.

Изменение микроструктуры вдоль радиуса, по зонам, обсуждалось в [3]. В исходном состоянии (до нагружения) сталь имела феррито-перлитную структуру с содержанием перлита $\sim 20 \%$. В свободном феррите образовались многочисленные пластины толщиной 0,5 мкм и менее. Давление ударной волны превышало давление $\alpha \rightarrow \varepsilon$ перехода (11 ГПа), образующаяся $\varepsilon$-фаза превращалась при разгрузке в $\alpha$-фазу. Поэтому пластины представляют собой следы цикла $\alpha \rightarrow \varepsilon \rightarrow \alpha$ превращений, проходящих на первом этапе нагружения (рис. $9 a$, б). Границы пластин могут быть как малоугловыми, так и большеугловыми. Искривленная форма пластин обусловлена деформацией на втором этапе. В феррите перлита следов $\alpha \rightarrow \varepsilon$ превращения не наблюдалось, возможно, из-за малой толщины ферритных пластин. В феррите перлита наблюдается повышенная плотность дислокаций и наноразмерные частицы выделений. Пластины цементита почти не деформируются, хотя удлиненная форма перлитных участков свидетельствует о деформации перлита.

Структура второй зоны (рис. $9 a, b, 2$ ) существенно отличается от структуры первой. При металлографическом исследовании видно (рис. 9 в), что на месте зерен исходного свободного феррита возникли новые мелкие участки, внутри которых видны дисперсные пластинки. Примеры таких участков указаны стрелками на рис. 9 в. При большом увеличении видно (рис. 9 2), что структура состоит из субмикрокристаллических пластин толщиной около 200 нм, которые имеют тенденцию выстраиваться в ряды. Микротвердость в этой зоне резко возрастает (рис. 8 б) и становится равной твердости закаленной стали. Характер микроструктуры, высокая микротвердость и резкая граница первой и второй зон дают основание считать, что во второй зоне в свободном феррите на втором этапе нагружения происходило образование аустенита и последующая резкая закалка, т. е. проходил цикл $\alpha \rightarrow \gamma \rightarrow \alpha$ превращений. Превращение при нагреве вызвано совместным действием повышенной температуры и давления при деформации сжатия, а закалка - резким «сбросом» давления. В феррите пер- 
лита наблюдается повышенная плотность дислокаций и наноразмерные выделения, а также появляются новые границы, что указывает на прохождение превращений. Пластины цементита изгибаются, но деформируются слабо.

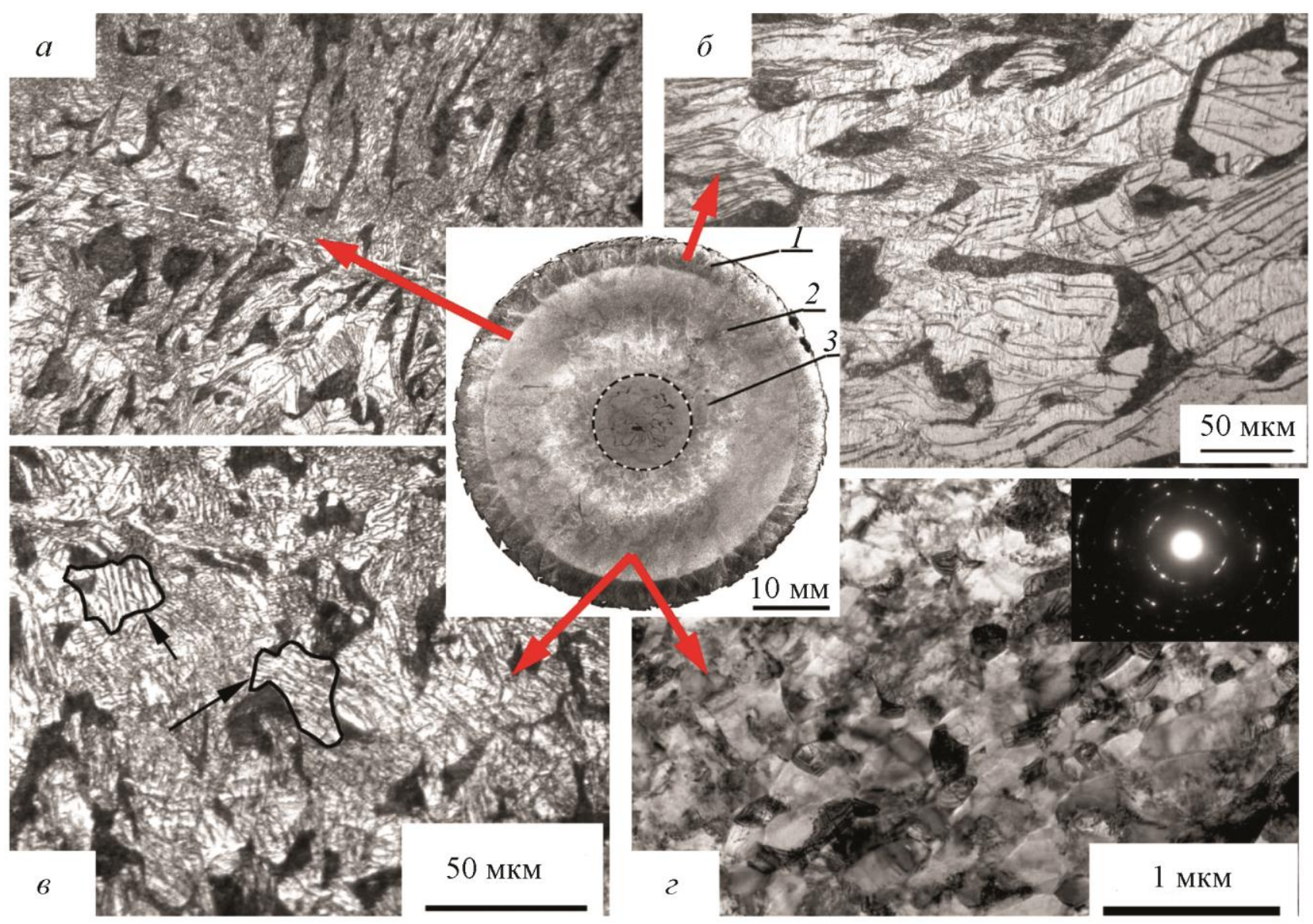

Рис. 9. Граница 1-й и 2-й зон (a) и микроструктура 1 -й $(б)$ и 2-й зоны $(6,2)$

В области перехода от второй к третьей зоне структура свободного феррита неоднородна. На рис. 10 а представлена структура, сходная со структурой феррита во второй зоне, но размер зерен больше и составляет 300-500 нм. Зерна содержат повышенную плотность дислокаций. На рис. $10 б$ показан участок полностью рекристаллизованной структуры, размер зерен около 500 нм. Микротвердость в этой области уменьшается (рис. 8 б). Пластины цементита в перлите имеют переменную толщину и неоднородный контраст (рис. 10 в), что указывает на начальные стадии растворения цементита. Феррит перлита разбивается на отдельные участки, которые, как показывает электронограмма, имеют различную ориентацию. Эти наблюдения свидетельствуют о дальнейшем повышении температуры в данных участках, расположенных ближе к оси цилиндра. На рис. 10 г показана структура на границе исходной перлитной колонии. Видны рекристаллизационные процессы в свободном феррите и феррите перлита, а также изменение состояния цементита. 


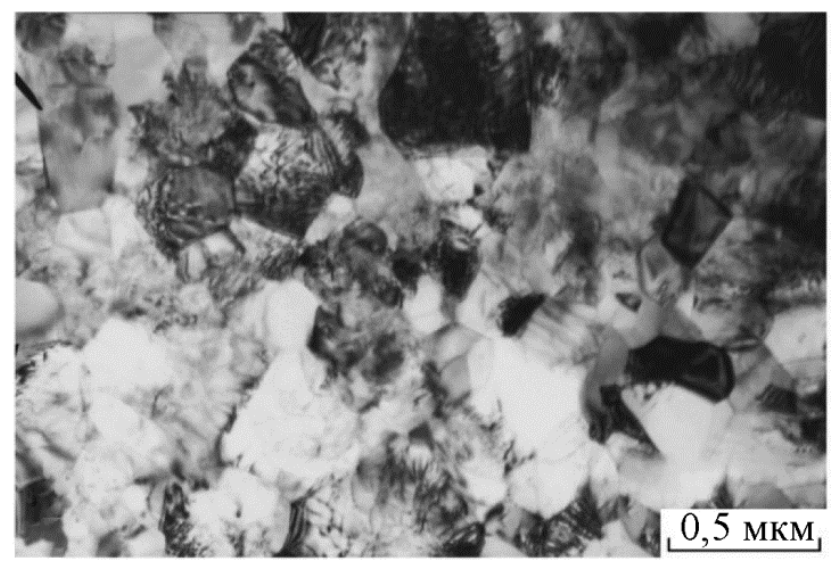

$a$

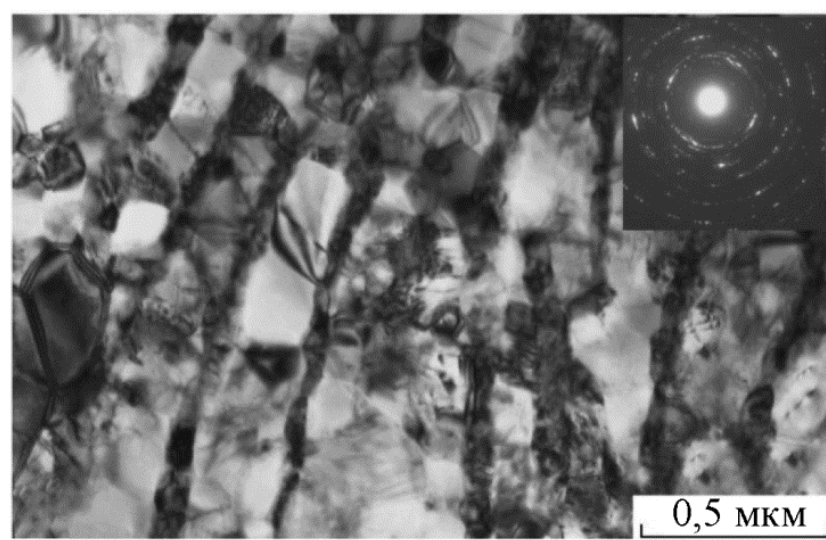

B

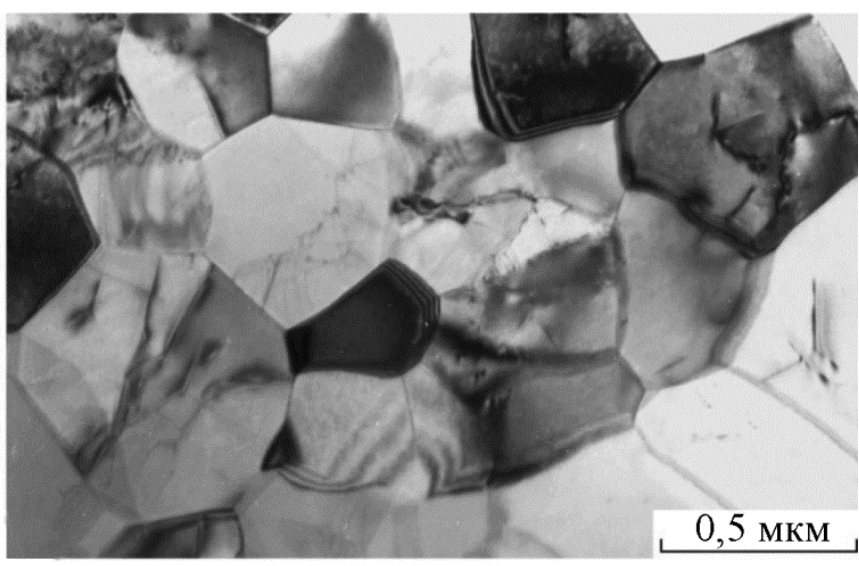

6

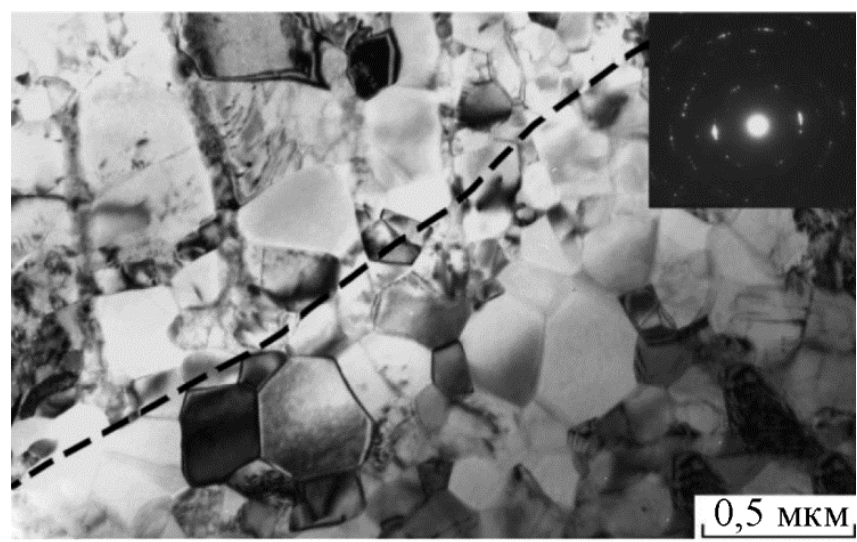

2

Рис. 10. Структура в области перехода от второй к третьей зоне. Субмикрокристаллическая структура феррита $(a)$, рекристаллизованные зерна феррита (б), перлит (в) и граница феррит/перлит (2)

Структура третьей зоны (рис. 11) свидетельствует о продолжающемся повышении температуры. Микротвердость снижается до значений твердости стали в отожженном состоянии. При металлографическом исследовании видно (рис. 11 a), что в начале зоны на месте свободного феррита возникают новые мелкие зерна в результате цикла $\alpha \rightarrow \gamma \rightarrow \alpha$ превращений. Участки перлита удлиняются при деформации, но не превращаются в аустенит. По мере повышения температуры начинается превращение перлита в аустенит. На рис. $11 \sigma$ видно, что границы перлитных участков становятся размытыми и неровными, внутри участков появляются светлые «точки». Наконец, происходит полное превращение исходной ферритоперлитной структуры в аустенит и при охлаждении на границах новых мелких зерен образуются многочисленные участки нового перлита (примеры указаны стрелками на рис. 11 в). При большом увеличении видно (рис. 11 2), что межпластиночное расстояние в новом перлите меньше, чем в исходном. В отдельных местах наблюдается сфероидизация цементита (рис. 11 d). Расположение частиц цементита сохраняет направленность исходных пластин. Повидимому, для растворения цементита в аустените не хватает времени пребывания при высокой температуре. Важно отметить, что в центре цилиндра отсутствуют следы плавления и последующей кристаллизации. Следовательно, температура не превышает температуру плавления стали $\left(\sim 1530{ }^{\circ} \mathrm{C}\right)$, но выше температуры конца аустенитизации $\left(\sim 880^{\circ} \mathrm{C}\right)$. 


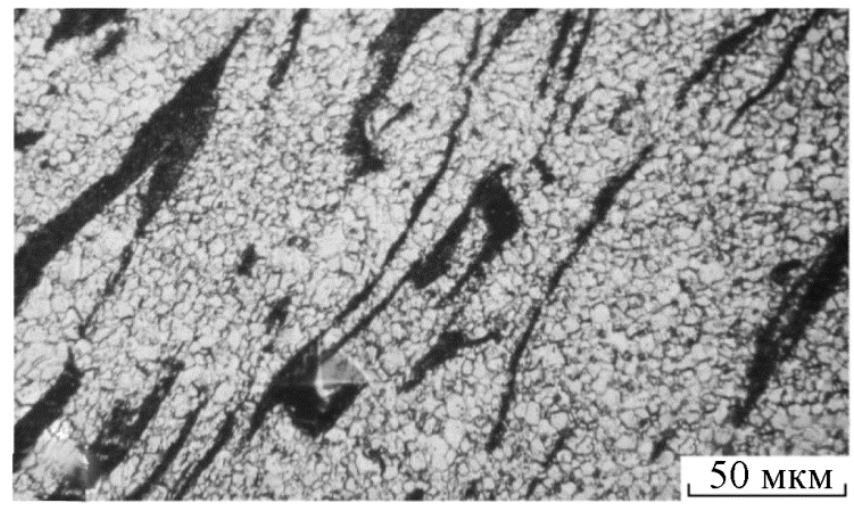

$a$

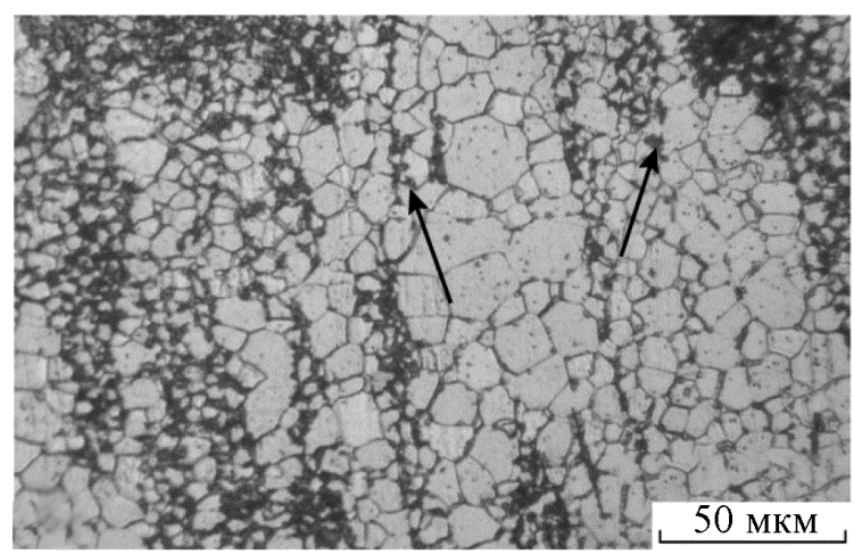

B

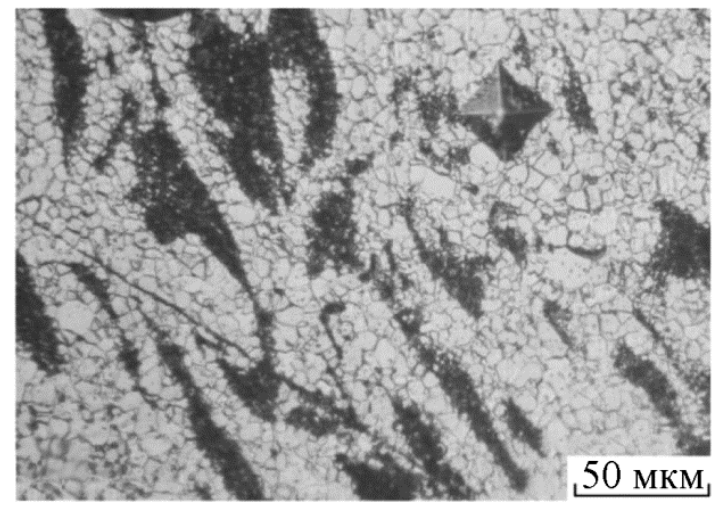

6

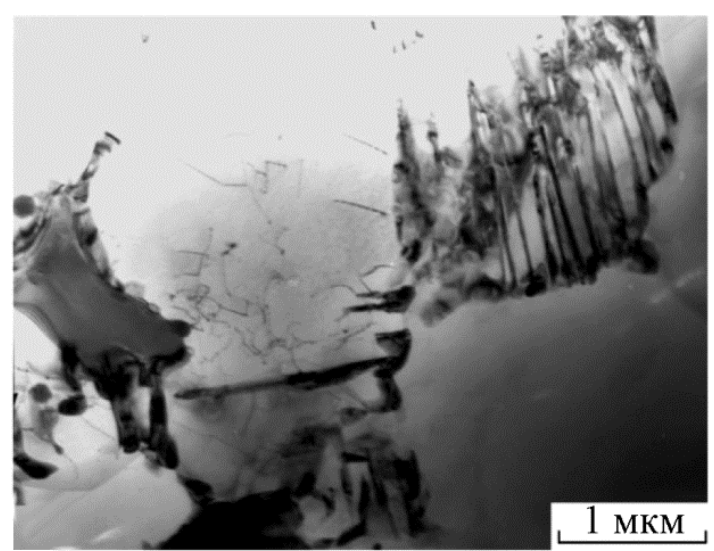

2

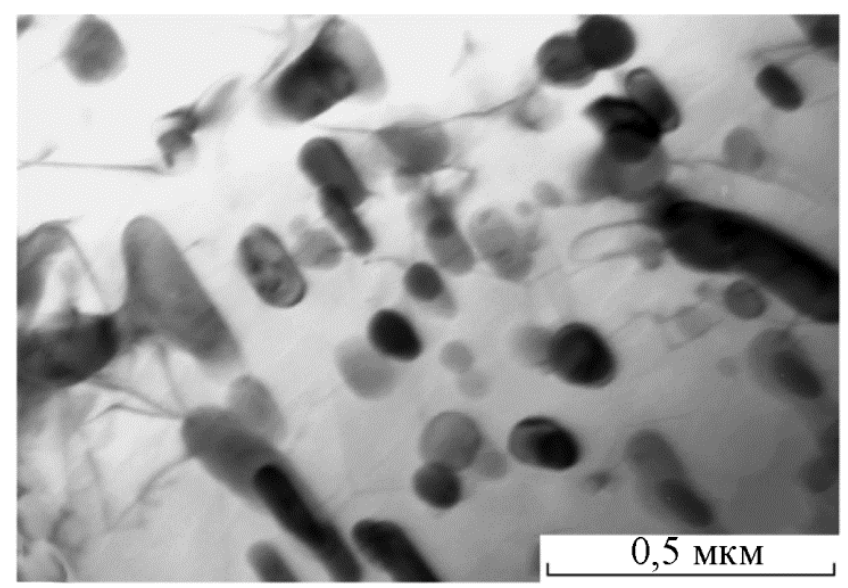

$\partial$

Рис. 11. Структура третьей зоны. Новые зерна в феррите, 12 мм от оси цилиндра $(a)$, начало превращения перлита в аустенит, 10 мм от оси (б), образование нового перлита, 8 мм от оси $(6,2)$, сфероидизация цементита $(\partial)$

Как и в случае медной оболочки, степень радиальной деформации и истинную радиальную деформацию легко определить, используя взаимосвязь расположения точек на оболочке и цилиндре.

Вид радиальной зависимости деформации представлен на рис. 12. Видно, что деформация существенно возрастает при приближении к оси цилиндра. На расстоянии 6-8 мм 
от оси цилиндра устойчивость схождения нарушается, и движение перестает быть осесимметричным (рис. 8 a), поэтому расчетная кривая в этой области обозначена пунктиром.

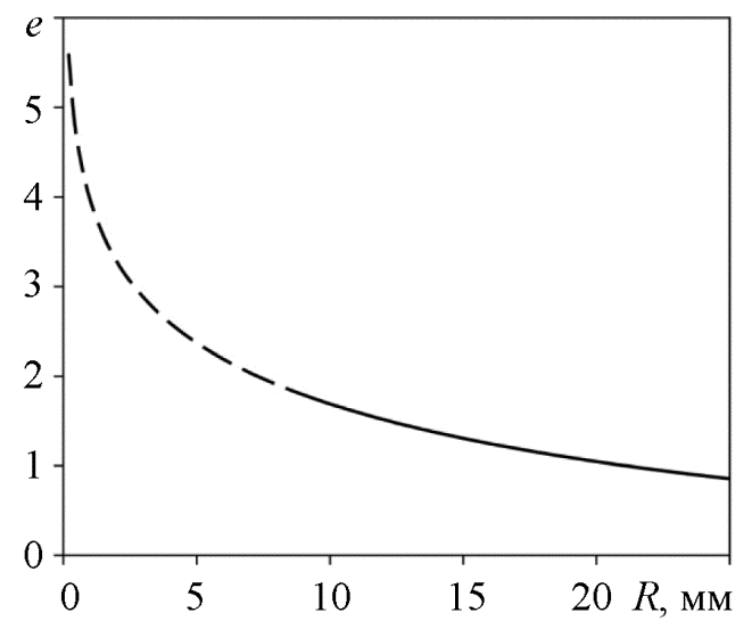

Рис. 12. Зависимость радиальной деформации от радиуса в стальной оболочке

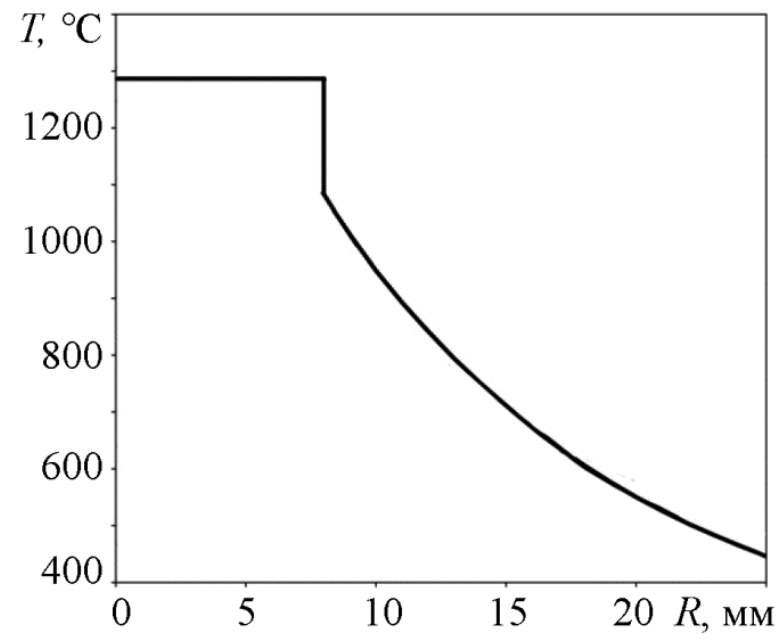

Рис. 13. Радиальная зависимость температуры в стальной оболочке

Расчет повышения температуры вследствие высокоскоростного деформирования оболочки при инерционном схождении проводили следующим образом. Из результатов рентгеновской регистрации процесса нагружения известна массовая скорость оболочки, следовательно, известна приобретенная ей под действием ударной волны кинетическая энергия. Как уже отмечалось, эта энергия затрачивается на деформирование оболочки и практически вся переходит в теплоту. Как и в медной оболочке, температуру считали пропорциональной деформации. В области осесимметричного движения температура плавно возрастает по мере приближения к оси. Вблизи оси $(r<8$ мм), в области неустойчивого схождения, можно говорить лишь об усредненной температуре, соответствующей внесенной в эту область энергии. Коэффициент пропорциональности между температурой и деформацией, в отличие от медной оболочки, рассчитывали не по реперным точкам, а из условия нормировки: тепловая энергия цилиндра равна кинетической энергии оболочки, приобретенной под действием взрыва. Необходимо отметить, что наличие зоны неустойчивости вблизи оси цилиндра никак не влияет на деформацию и, следовательно, на температуру внешней осесимметричной зоны. Поэтому сначала проводится расчет температуры для идеального схождения - так, как если бы зоны неустойчивости не существовало. Деформация и температура вблизи оси в этом случае стремятся к бесконечности, однако теп- 
ловая энергия остается конечной. Далее температура в области неустойчивого движения усредняется, при этом за счет вклада расположенных на малых радиусах горячих областей возникает скачок температуры $\sim 300{ }^{\circ} \mathrm{C}$ на границе зон неустойчивого и осесимметричного движения. Вид радиальной зависимости температуры в стальной оболочке приведен на рис. 13.

Оценим параметры нагружения медной оболочки, используя эталонные данные, полученные при регистрации процесса схлопывания стальной оболочки и полученные распределения температур. Сравним изменение температуры вдоль радиусов схлопнувшихся медной (рис. 6) и стальной (рис. 13) оболочек. Видно, что температуры на внешней поверхности полученных цилиндров и на произвольных относительных радиусах (например, 1/2 или 1/3 радиуса цилиндра) различаются приблизительно вдвое. Следовательно, также соотносятся удельные тепловые энергии медного и стального цилиндров. Так как тепловая энергия цилиндра равна приобретенной под действием взрыва кинетической энергии оболочки с учетом различия удельных теплоемкостей меди и стали (385 и 460 Дж/кг К) и плотностей (8900 и 7800 кг/м $\left.{ }^{3}\right)$, соответственно удельная кинетическая энергия и массовая скорость медной оболочки были меньше приблизительно в 2,4 и 1,6 раза соответственно. Так как массовая скорость стальной оболочки была 0,8 км/с, скорость медной оболочки составляла $\sim 0,5 \mathrm{kм} / \mathrm{c}$. Соответствующее этой скорости давление в ударной волне (с учетом эффекта удвоения массовой скорости при выходе ударной волны на свободную поверхность), по данным [10], равняется 10 ГПа.

Неустойчивость. Как было отмечено выше, в структуре медной оболочки большого диаметра заметных эффектов неустойчивости радиального течения не наблюдалось. В стальной оболочке имела место потеря устойчивости вблизи оси в зоне радиусом менее 8 мм. Эта неустойчивость развивалась на внутренней поверхности оболочки. Помимо этого, в наружной зоне толщиной цилиндра $\sim 4$ мм обнаружены эффекты локализованной деформации. Е.И. Забабахин отмечал [1], что «при схождении толстой сферической оболочки вблизи поверхности происходят сильные сдвиговые деформации». Локализация деформации происходит путем периодических сдвигов под углами около 60 градусов к цилиндрической поверхности. Сдвиги приводят к возникновению в поверхностном слое участков в виде равносторонних треугольников (рис. $14 a$ и б). На боковой поверхности цилиндра образуются трехгранные призмы, создающие ребристую поверхность (рис. 14 в). Локализованная сдвиговая деформация выявляется в микроструктуре по сильному удлинению перлитных участков, которые выглядят тонкими черными линиями (рис. 14 б). Возникшие треугольники свидетельствуют об отклонении течения материала вблизи внешней поверхности от «идеального» радиального.

Сравним наблюдающиеся картины течений в оболочках большого диаметра с течениями в медной оболочке меньшего диаметра. На рис. 15 приведен рентгеновский снимок сходящейся оболочки диаметром 48 мм. По результатам рентгеновской регистрации массовая скорость схождения оболочки составляет 0,5 км/с, т. е. такая же, как у медной оболочки большего диаметра. По расстоянию, пройденному средней линией оболочки при схлопывании, и скорости схождения находим среднее время схождения. Оно составляет 30 мкс, что практически совпадает с измеренным временем схождения стальной оболочки. 


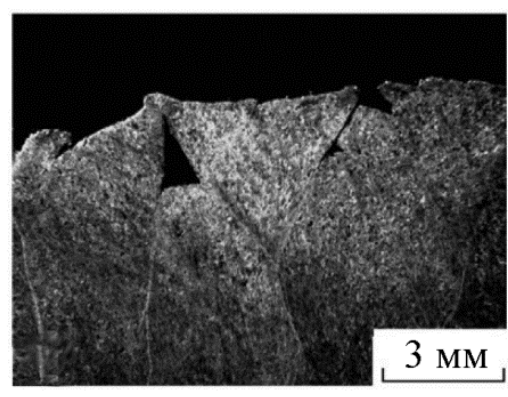

$a$

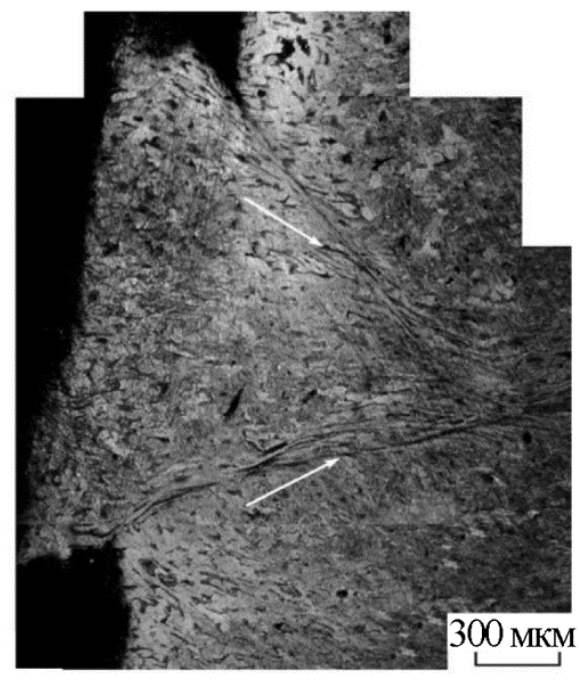

6

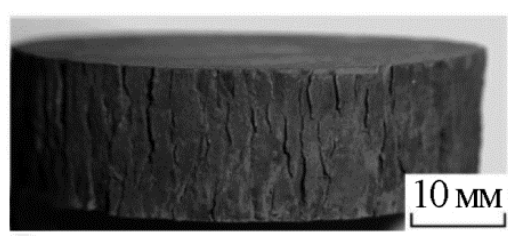

B

Рис. 14. Локализованная деформация в поверхностном слое стальной оболочки. Макроструктура (a) и микроструктура (б) в поперечном сечении и поверхность цилиндра ( 6 ). Стрелками указаны полосы локализованного сдвига

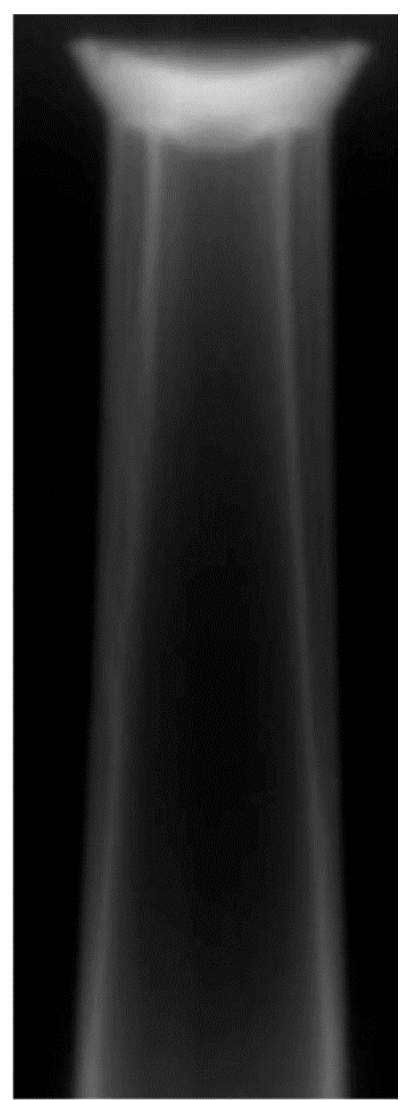

Рис. 15. Схождение медной оболочки внутренним диаметром 40 мм.

Рентгеновская регистрация

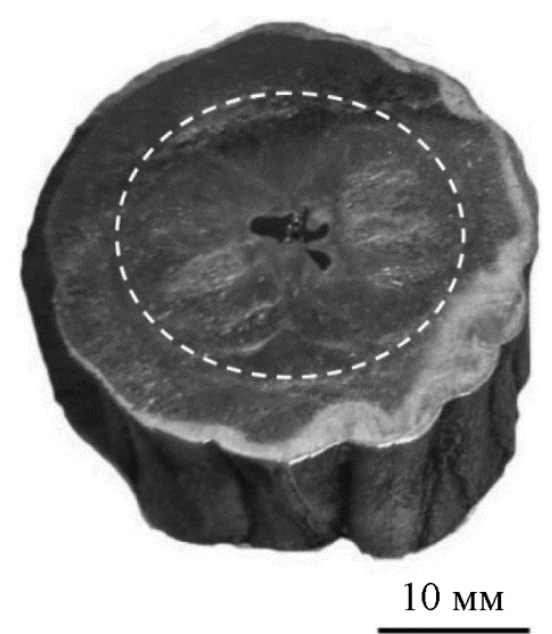

Рис. 16. Макроструктура поперечного сечения схлопнутой оболочки внутренним диаметром 40 мм

Макроструктура цилиндра, полученного при схлопывании оболочки, представлена на рис. 16. В структуре можно выделить две характерные области (разделены пунктирной линией), течение в которых различается. Во внутренней зоне образовалась симметричная фигура в виде цветка, состоящая из чередующихся удлиненных участков с большой степе- 
нью деформации и участков, деформированных слабее. Характерная микроструктура в этих участках представлена на рис. 17. В сильно деформированных участках - «лепестках» цветка, (рис. 17 a) видны следы течения преимущественно ламинарного характера, в слабо деформированных участках (промежутках между «лепестками»), (рис. 17 б) видны удлиненные в радиальном направлении зерна с многочисленными двойниками. То есть в отличие от стальной оболочки (рис. 8 a), течение в зоне неустойчивости в центральной части образца не было хаотическим турбулентным, а носило закономерный характер. Другое отличие состоит в том, что центральная область неосесимметричного течения занимает более четверти объема полученного при схлопывании цилиндра.

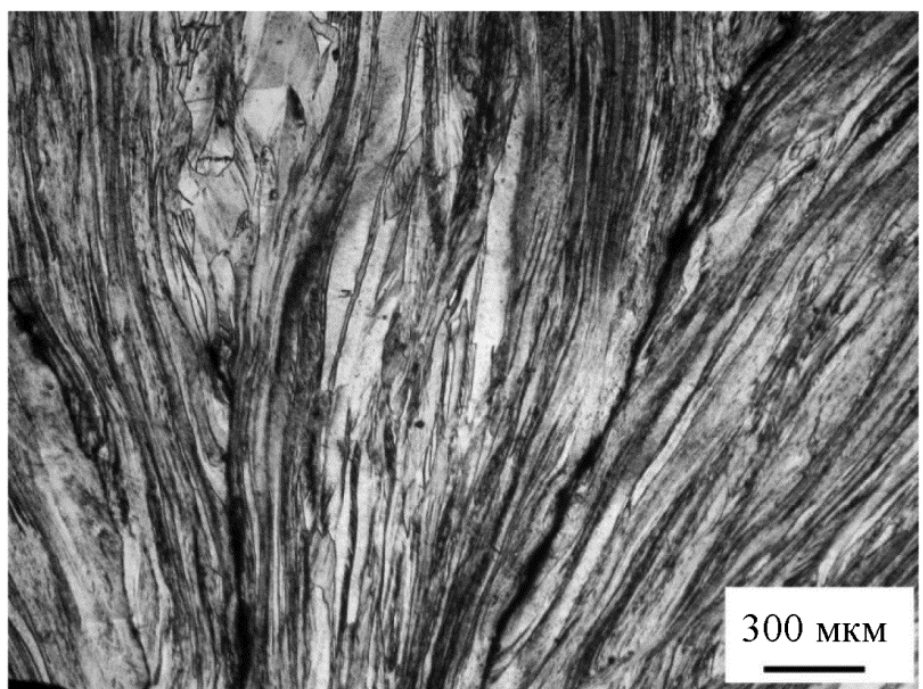

$a$

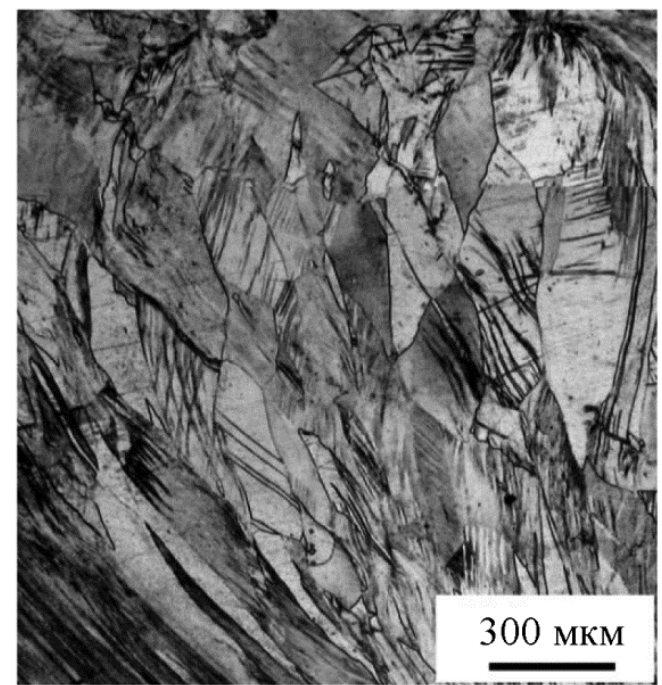

$\sigma$

Рис. 17. Микроструктура в участках с сильной локализованной деформацией $(a)$ и между ними (б) в центральной части оболочки

Деформация во внешней зоне оболочки также не являлась строго осесимметричной. Поверхность полученного при схлопывании цилиндра представляет собой чередующиеся выпуклые волны и впадины (рис. 16). На поверхности насчитывается 9-14 таких волн. Как и в стальном образце, неустойчивость радиальной деформации во внешних слоях данной оболочки, по-видимому, обусловлена сдвиговыми напряжениями, возникающими при схождении. Под действием этих напряжений происходит локализация деформации в виде полос, исходящих из впадин и отклоненных от радиального направления на углы $\sim 30^{\circ}$. Однако если в стальном цилиндре вдоль полос сдвига происходило разрушение с последующим выдавливанием приведенных на рис. 14 треугольных призм, то в медном образце такого эффекта не наблюдалось. Как видно на рис. 16, полосы в меди гораздо более широкие, вследствие чего локализация деформации оказывается существенно меньше. Вместо выдавливания треугольных участков имеют место плавные изгибы, приводящие к формированию округлых выступов на поверхности оболочки.

В промежуточной области, разделяющей внутреннюю и внешнюю части схлопнутой оболочки (зона вблизи пунктирной линии на рис. 16), расположены многочисленные залеченные поры и трещины, радиальный характер деформации нарушается возникновением разнообразных структур залечивания. Деформированная структура крайне неоднородна и выглядит хаотической. Возникновение этой неоднородности, также, как и возникновение тангенциальных трещин в медной оболочке большего диаметра (рис. 1, 3), по-видимому, обусловлено залечиванием повреждений, связанных с откольными явлениями при выходе ударной волны на внутреннюю поверхность оболочки. 
Отметим, что число выступов на поверхности медной оболочки малого диаметра колеблется в пределах от 9 до 14. Столько же выступов при схождении медных оболочек приведено в монографии В.А. Огородникова [4]. Объяснение количества выступов отсутствует, приведенные в [4] расчеты не дали согласия с экспериментом.

\section{4. Заключение}

Таким образом, сравнительное исследование структуры трех сошедшихся оболочек позволило установить следующие закономерности процесса схождения.

1. Во всех оболочках наблюдается радиальное изменение структуры и микротвердости, связанное с повышением степени деформации и температуры по мере приближения к оси схождения. В структуре поперечных сечений цилиндров, полученных из медной и стальной оболочек большого диаметра, обнаружено три кольцевые зоны. В меди это зоны деформации, рекристаллизации и плавления; в стали наличие трех зон обусловлено не только деформацией, но и $\alpha \rightarrow \varepsilon \rightarrow \alpha$ и $\alpha \rightarrow \gamma \rightarrow \alpha$ циклами превращений. В медной оболочке малого диаметра радиальное изменение микруструктуры связано с локализацией деформации, поразному протекающей на различных радиусах.

2. Схождение оболочек большого диаметра в целом более устойчиво. В медной оболочке заметных эффектов, связанных с неустойчивостью, не наблюдается; в стальной оболочке присутствуют следы неустойчивого хаотического радиального течения вблизи оси (на радиусах менее 7 мм) и закономерная локализованная деформация сдвигового характера вблизи поверхности. Схождение медной оболочки малого диаметра менее устойчиво, закономерная локализованная деформация имеет место на всех радиусах, однако вид течений изменяется по мере приближения к оси фокусировки. Локализация вблизи поверхности, также как в стальном цилиндре, обусловлена сдвиговыми напряжениями, но значительная ширина полос сдвига и наличие изгибной составляющей деформации приводит к другой (волнообразной) форме наблюдаемых на поверхности возмущений. Таким образом, неустойчивость схождения зависит как от свойств материала, так и от диаметра оболочки. Важно подчеркнуть, что в относительном масштабе (отношение толщины стенки к диаметру оболочки) рассмотренные оболочки большого диаметра являются более тонкостенными, чем оболочка меньшего диаметра. То есть, если бы устойчивость схождения определялась безразмерным отношением толщины стенки к диаметру оболочки, схождение малой оболочки должно было быть не менее, а более устойчивым. В итоге полученные экспериментальные результаты свидетельствуют о том, что устойчивость схождения зависит не от относительных, а от абсолютных размеров оболочки.

3. Откольные явления, связанные с выходом ударной волны на свободную внутреннюю поверхность оболочки, проявляются в микроструктуре полученных медных цилиндров в виде тангециальных трещин и следов залечивания, но не проявляются в структуре стального цилиндра. Поскольку откол происходит тогда, когда растягивающие напряжения, возникающие при выходе ударной волны остроконечного профиля на свободную поверхность, превышают динамический предел прочности материала [8], отсутствие следов откольных повреждений в стальном цилиндре можно объяснить более высокой прочностью стали по сравнению с медью. Иными словами, развиваемые в рассматриваемых экспериментах растягивающие напряжения превышают откольную прочность меди, но не превышают откольную прочность стали.

4. Результаты исследования показали, что сопоставление результатов экспериментов по схлопыванию оболочек из различных материалов позволяет частично воссоздать условия нагружения, не регистрировавшиеся непосредственно в ходе эксперимента, в частности, вычислить массовую скорость оболочки и давление во фронте ударной волны. 


\section{Благодарность}

Электронно-микроскопическое исследование выполнено на оборудовании ичентра коллективного пользования в Испытательном иентре нанотехнологий и перспективных материалов ИФМ УрО РАН.

Работа выполнена при поддержке Комплексной программы УрО РАН (проект 18-10-2-39).

\section{Литература}

1. Забабахин Е. И., Забабахин И. Е. Явления неограниченной кумуляции. - М. : Наука, 1988. - $172 \mathrm{c}$.

2. Иванов А. Г., Огородников В. А., Тюнькин Е. С. Поведение оболочек под действием импульсной нагрузки. Малые возмущения // Журн. прикл. механики и техн. физики. 1992. - № 6. - С. 112-115.

3. Deformation- and temperature-related processes that occur upon the collapse of a thick cylindrical shell made of steel 20 / V. I. Zeldovich, N. Yu. Frolova, A. E. Kheifets, S. M. Dolgikh, K. V. Gaan, E. V. Shorokhov // Physics of Metals and Metallography. - 2015. - Vol. 116. P. 285-292. - DOI: 10.7868/S001532301503016X.

4. Огородников В. А. Вязкость и ее роль в динамических процессах. - Саров : ФГУП «РФЯЦ-ВНИИТФ», 2012. - 239 с.

5. Ударные волны и явления высокоскоростной деформации металлов / под ред. М. А. Мейерса, Л. Е. Мурра. - М. : Металлургия, 1984. - 512 с.

6. Rybin V. V., Ushanova E. A. Features of twinning under high-speed loading conditions during explosion welding // Letters on Materials. - 2013. - Vol. 3(2). - P. 145-149. DOI: $10.22226 / 2410-3535-2013-2-145-149$.

7. Рыбин В. В., Ушанова Э. А., Золоторевский Н. Особенности строения разориентированных структур в бислойной пластине медь-медь, полученной сваркой взрывом // Журнал технической физики. - 2013. - Т. 83, вып. 9. - С. 63-72.

8. Зельдович Я. Б., Райзер Ю. П. Физика ударных волн и высокотемпературных гидродинамических течений. - М. : Физматгиз, 1963. - 632 с.

9. Метод исследования особенностей высокоскоростного деформирования металлов на микро- и мезомасштабных уровнях / В. С. Глазков, О. Н. Игнатова, А. Н. Малышев и др. // Физическая мезомеханика. - 2010. - Т. 13, вып. 3. - С. 61-68.

10. Shock Wave Data Base (База данных института теплофизики экстремальных состояний Объединенного института высоких температур РАН, г. Москва, Россия). URL: http://www.ihed.ras.ru/rusbank/ 